\title{
PRECISIONES SOBRE LA CAPILLA DE SAN DIEGO DE ALCALÁ, EN SANTA MARÍA DE JESÚS DE ALCALÁ DE HENARES
}

En un artículo aparecido recientemente en esta revista (vol. 81, núm. 324, págs. 379-394), J. M. Cruz Yábar analiza una traza (fig. 1) para el retablo mayor de la capilla San Diego del convento en Santa María de Jesús de Alcalá de Henares, y busca rectificar la atribución a Alonso Cano propuesta por Alfonso Pérez Sánchez en 1986, cuando el dibujo formaba parte de una colección particular florentina ${ }^{1}$. Basándose en una foto del dibujo que no se ha sacado del original y desconociendo la ubicación actual (pues el autor cree erróneamente que sigue estando en Florencia), Cruz Yábar propone como el verdadero autor de esta traza a un arquitecto no demasiado conocido, Sebastián de Benavente.

Pues bien, es importante precisar que en el mismo año que Pérez Sánchez publicó el mencionado dibujo, éste fue vendido a The Morgan Library \& Museum (1986.46) con sede en el corazón de Manhattan, donde desde entonces se conserva formando parte de la renombrada colección de dibujos que posee esta institución. Es más, los datos referidos de la mencionada traza se encuentran disponibles en la propia página web de la Morgan Library con atribución a Sebastián de Herrera Barnuevo. Se trata de un dibujo de grandes dimensiones - 117,6 $\times 62,9 \mathrm{~cm}-$, ejecutado con pluma y tinta parda y aguada gris-azul, estando el papel que lo contiene formado por varios trozos unidos y reforzado por lienzo.

Considero que este no es el momento de defender la atribución de esta traza a Cano que figurará en una exposición de dibujos españoles que organiza The Frick Collection. Por ello, solo me detendré a comentar con brevedad tres cuestiones que se deducen de la sola observación del original. En primer lugar, cabe señalar que la fotografía que acompaña el artículo de Cruz Yábar no reproduce la composición completa del dibujo al faltar su parte inferior; corta la parte de debajo, donde lucen los escudos reales ${ }^{2}$. Por otra parte, y lo que es más importante, es de destacar que en la misma traza se están ofreciendo dos opciones para el diseño y ejecución del retablo (véanse, por ejemplo, los dos putti del remate y las figuras de los intercolumnios), pues una de sus mitades propone una solución pictórica y la otra mitad, una escultórica ${ }^{3}$. Esto suscita dudas sobre el hecho de que se trate de una copia de la traza definitiva efectuada por Benavente para guardar en su taller; parece más bien, que estaríamos ante un dibujo de presentación realizado para que los comitentes pudieran elegir entre dos posibles soluciones. Finalmente, sólo resta apuntar que el estilo y la técnica del dibujo son de una calidad excepcional y que los efectos sutiles de la aguada — no del todo apreciables en una fotografía - únicamente pudieron salir del pincel de un maestro dibujante.

JONATHAN BROWN

Institute of Fine Arts, New York University

\footnotetext{
${ }^{1}$ Pérez SÁncheZ, Alfonso, Historia del dibujo en España. De la edad media a Goya (Madrid, 1986), p. 224, con la fecha de $1648-50$.

${ }^{2}$ La hoja entera se reproduce en Zurbarán, Madrid, 1988, p. 330, y en AgUlLó y CoBO, Mercedes, "El Convento de San Diego de Alcalá", Cuadernos de Arte e Iconografía 23(2003), pp. 3-76. fig. 1.

${ }^{3}$ Agulló y CoBo, p. 12, reconoce que el dibujo ofrece dos soluciones para el diseño del Altar.
} 